\title{
Laparoscopic ureterolithotomy for large lower ureteral stone: a case series report
}

\author{
Hamidreza Zia, Seyed Saeed Tamehri Zadeh, Fatemeh Khatami and Seyed Mohammad Kazem Aghamir
}

\begin{abstract}
Background: Identifying the precise location of the lower ureter is crucial in not only ureteral surgeries but also the other surgeries that may cause ureteral injury. Although a variety of approaches have been applied to detect the location of the lower ureter, the majority of them had an association with several complications or be difficult to perform perfectly or be time-consuming.

Case presentation: Seven patients with distal ureteric stones of the size ranged from 2 to $3 \mathrm{~cm}$. All patients entered the study after signing the informed consent, and the case report is based on CARE guidelines. After specifying the inner ring of the inguinal canal, the posterior peritoneum was opened and dissected from an area of $2 \mathrm{~cm}$ medial and $2 \mathrm{~cm}$ inferior to the inner ring. Thereafter, the stone was extracted from the precise location of them, which was identified by ureteral pinching.

Conclusion: We assumed that we were easily able to identify the site of the lower ureter through $2 \mathrm{~cm}$ medial and $2 \mathrm{~cm}$ inferior to the inner ring. The result of our study on seven patients demonstrated that this maneuver can minimize the time of surgery and no complications have been seen while this approach was applied.
\end{abstract}

Keywords: Laparoscopic ureterolithotomy, Surgery, Case series

\section{Background}

In the last decades, the emergence of new methods and techniques has revolutionized the management of ureteral stones and minimize the demand for open surgery, which often are accompanied by severe complications [1]; nonetheless, in some situations, open surgery may be necessitated instead of endoscopic treatments. There is an increased tendency toward laparoscopic ureterolithotomy (LUL) owing to more promising outcomes, lower odds of morbidities, and less invasive in comparison with open surgery; hence, LUL can be substituted to open surgery $[2,3]$.

Removing the lower third of ureter stones with LUL was not as successful as that in upper and middle ureteric stones [4], and it is conceivable that in upper and mid-ureteric stones, the preferable approach is

*Correspondence: mkaghamir@tums.ac.ir

Urology Research Center, Tehran University of Medical Sciences, Tehran, Iran retroperitoneal, however, for lower ureteric stones, transperitoneal approach has an association with better results [5]. Given the difficulties of detecting lower ureter during laparoscopic surgery, this study aimed at assessing the efficacy of a new approach to surpass those problems in patients with lower ureteric stones.

\section{Therapeutic intervention}

Seven patients with distal ureteric stones of the size of the upper $2 \mathrm{~cm}$ (below the lower sacroiliac joint) candidate for LUL because of failed urethroscopy in 4 patients or very large stone in three patients. The patients were put in a 15 Trendelenburg and 30 lateral positions, and a 10-mm laparoscopic port above the umbilical to insert the camera, which was performed via open surgery. A 5-mm port parallel to the first port under vision was inserted in the iliac fossa and another 5- $\mathrm{mm}$ port in the suprapubic area. After specifying the inner ring of the inguinal canal (Fig. 1), the posterior peritoneum was opened and dissected from an area of $2 \mathrm{~cm}$ medial and 


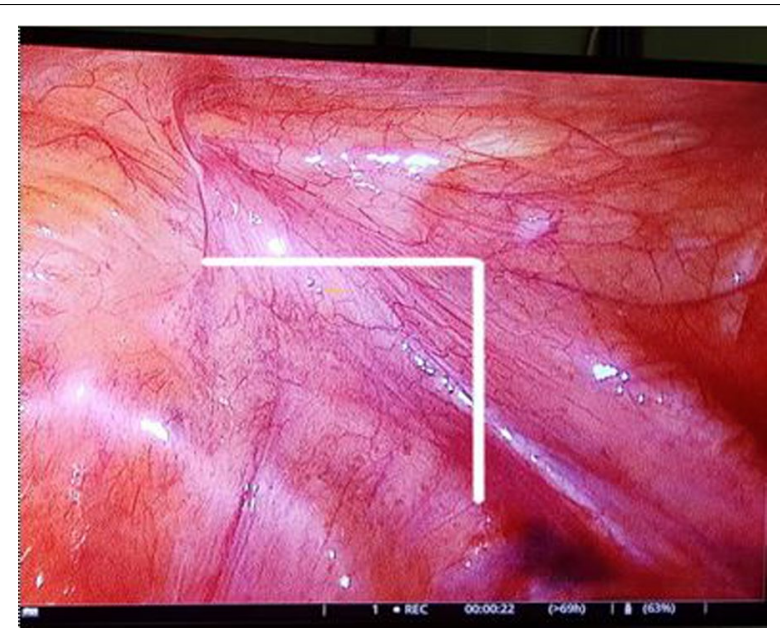

Fig. 1 The inner ring of inguinal canal

$2 \mathrm{~cm}$ inferior to the inner ring (Fig. 2). Thereafter, the stone was extracted from the precise location of them, which was identified by ureteral pinching (Fig. 3). Once the stone was removed from the distal ureter, double J was safely inserted and the incision was sutured by proline $4 / 0$. In the end, the drain was implanted and maintained until the output became zero.

\section{Case presentation}

Following Jan 201820 Feb 2020, 7 patients (5 men, 2 female) with the mean age of $40.85 \pm 18.67$ years without any history of abdominal surgery underwent LUL in our institute. All patients entered the study after signing the informed consent, and the case report is based on CARE guidelines. Five patients suffered from left ureteral stones, and the rest of them suffered from right ureteral

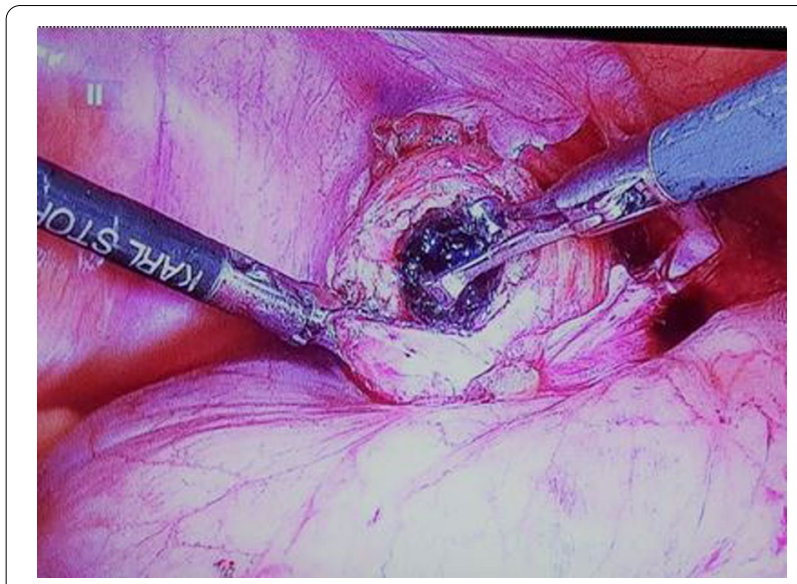

Fig. 2 Dissecting the posterior peritoneum

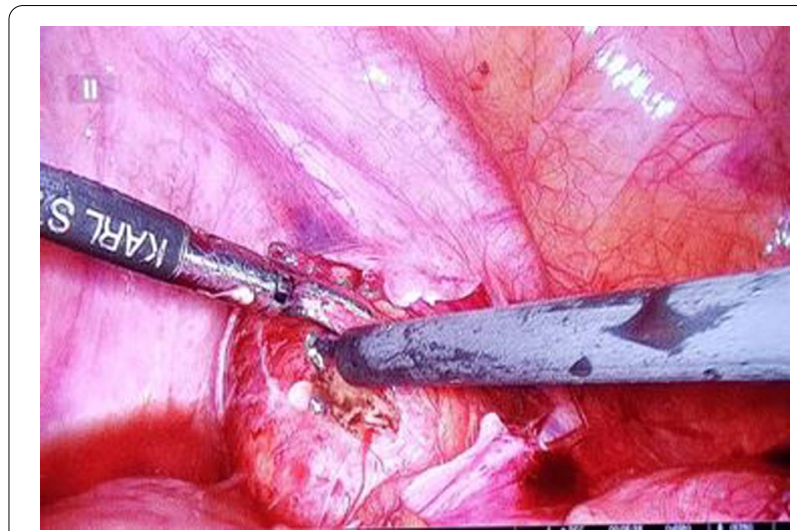

Fig. 3 Stone extraction

stones. Four patients mentioned the history of transurethral lithotripsy in the past (Table 1).

The average time to approach the ureter after inserting the ports was $4 \mathrm{~min}$, and the average time of surgery was approximately $52 \mathrm{~min}$. The average size of stones was about $2.5 \mathrm{~cm}$ of which ranged from 2 to $3 \mathrm{~cm}$. The mean length of hospitalization was 2.5 days (2-4 days). No intraoperative or postoperative complications were found, and all patients were discharged without any complication.

\section{Discussions}

The maneuver we utilized for detecting the location of the distal ureter was novel to the best of our knowledge and as we resulted by this study, it can provide simple fast access to the lower ureter without any complications that can be attributed to the approach.

A laparoscopic investigation of the ureter has been challenging and searching for a ureter may take so much time and be elusive. Professor Gaur and his colleagues designed a study on 101 patients, who were undergone laparoscopic ureterolithotomy. They reported that the ureter location of 71 patients was found without timewasting by using anatomical and pathological clues and also visualizing peristaltic waves. However, they stated that over 30 min was wasted regarding searching the ureter in 30 remaining patients, which was failed in six patients and the location of their ureter was detected digitally [6]. In the current, the mean time allocated for detecting lower ureter was $4 \mathrm{~min}$, which was considerably lower in comparison with the above study.

RK Low and his colleagues claimed that ureteral illuminator usage before surgery is capable of facilitating the ureter search, but, it was shown later that these catheters carry the risk of transient hematuria and rarely, reflex anuria [7]. Ureteral injury is one of the possible 
Table 1 All data of each patient

\begin{tabular}{|c|c|c|c|c|c|c|}
\hline Number & Sex & Age & Stone size $(\mathrm{cm})$ & $\begin{array}{l}\text { Time to approach the } \\
\text { ureter (min) }\end{array}$ & $\begin{array}{l}\text { Length of surgery } \\
\text { (min) }\end{array}$ & $\begin{array}{l}\text { Length of } \\
\text { hospitalization } \\
\text { (days) }\end{array}$ \\
\hline 1 & Male & 52 & 2 & 3 & 50 & 2 \\
\hline 2 & Female & 48 & 2.5 & 4 & 45 & 2 \\
\hline 3 & Female & 32 & 3 & 5 & 55 & 3 \\
\hline 4 & Male & 72 & 2.5 & 6 & 40 & 3 \\
\hline 5 & Male & 16 & 2.7 & 3 & 60 & 2 \\
\hline 6 & Male & 25 & 3 & 4 & 67 & 4 \\
\hline 7 & Male & 41 & 2.4 & 3 & 45 & 2 \\
\hline
\end{tabular}

complications of distal colectomies. It may be caused by misidentification of the anatomic landmarks during the left lateral dissection, due to factor pertaining to the patient, the disease, and the surgeon. This triangle consisted of (1) the dissected mesosigmoid (upper side), (2) upper mesorectum and sacral promontories (right side), (3) the margin of the incised posterior parietal peritoneum (lower side) [8]. A Mandhani identified a lower ureter in laparoscopic ureterolithotomy with an interesting method. The colon reflection helped them to identify iliac vessels and, therefore, the ureter location was not difficult to be identified [9].

The first laparoscopic retroperitoneal ureterolithotomy was carried out by Wickham in 1979, and 13 years later, the first laparoscopic transperitoneal ureterolithotomy was performed by Raboy and his colleges [10]. There is a scarcity of studies concerning laparoscopic ureterolithotomy, which probably is a result of tremendous advances that have occurred in the endoscopic methods and a high proportion of ureteral stones can be effectively handled with extracorporeal shockwave lithotripsy, ureteroscopy, and percutaneous nephrolithotomy [3]. Despite all of that, ureterolithotomy is the mainstay of ureteric stones treatment in selected cases including, but not limited to, impacted stones, large stones, cysteine stones, and especially stones located in the upper ureter and stones with these features, open surgery should be taken in consideration [11, 12]. Additionally, near $7 \%$ of ureteral stones, which were treated with endoscopic manipulation, were not treated completely and will need to be treated again [13] and eventually, approximately, $10 \%$ of them would be treated with open surgery [14].

Several reasons have been described in support of the idea that express ureterolithotomy with laparoscopy would be offered more advantages in comparison with open ureterolithotomy. On top of those, the feasibility of stone retrieval using laparoscopic ureterolithotomy in one session without any need to the additional procedure and consequently, in addition to patients indicated for that, lots of patients despite not complex stones, would rather this method [3]. The other superiority of laparoscopic ureterolithotomy to open ureterolithotomy are less injury, less discomfort following surgery, and shorter hospitalization [15].

As mentioned, the transperitoneal approach is beginning to appreciate in lower ureteric stones, which is due to the provided satisfactory working space and excellent access to the anatomical landmarks, as lower ureter can readily be detected $[9,16]$. On the other hand, to perform this procedure, a great amount of learning curve and experienced surgeon are warranted and apart from those, transperitoneal approach may result in intraperitoneal urine leakage [17].

Localizing the exact location of ureter stone sometimes is one of the leading difficulties that should be deal with. Bulging the proximal ureter enables to cause stone not to be seen properly, and if so, identifying the location of the stone is almost impossible. It has been postulated that pinching the ureter lightly with Maryland forceps aids surgeons to understand where must be incised. In our series, for all patients, this method was performed and stones localized without any problem.

Inserting double $J$ before or during the surgery with diminishing the risk of urinary extravasation and urinoma formation confers obvious benefits and is always recommended, and inflammation and impaction may hinder surgeons from performing that. Placing double $J$ right after stone extraction can also be beneficial by shortening the anesthesia time $[9,18]$.

\section{Conclusions}

We assumed that we were easily able to identify the site of the lower ureter through $2 \mathrm{~cm}$ medial and $2 \mathrm{~cm}$ inferior to the inner ring. The result of our study on seven patients demonstrated that this maneuver can minimize the time of surgery and no complications have been seen while this approach was applied. 


\section{Abbreviations}

CARE: CAse REporting; LUL: Laparoscopic ureterolithotomy.

\section{Acknowledgements}

We would like to thank Tehran University of Medical Sciences.

\section{Authors' contributions}

SMKA had main idea for this research and conceived the study. SSTZ and FK edited the manuscript. $\mathrm{HZ}$ wrote the first draft of the manuscript. All authors reviewed and edited the manuscript and approved the final version of the manuscript

\section{Funding}

There is no funding to report.

\section{Availability of data and material}

All data and information will be provided on request.

\section{Declarations}

\section{Ethics approval and consent to participate}

All patients entered the study after signing the informed consent and the case report is based on CARE guidelines.

\section{Consent for publication}

Written informed consent was obtained from the patient(s), and all data were analyzed and published anonymously.

\section{Competing interests}

All authors claim that there is no any conflicting interest in this case report.

Received: 11 June 2020 Accepted: 11 July 2021

Published online: 23 July 2021

\section{References}

1. Demirci D, Gülmez İ, Ekmekçioğlu O, Karacagil M (2004) Retroperitoneoscopic ureterolithotomy for the treatment of ureteral calculi. Urol Int 73(3):234-237

2. El-Feel A, Abouel-Fettouh H, Abdel-Hakim AM (2007) Laparoscopic transperitoneal ureterolithotomy. J Endourol 21(1):50-54

3. Fakhr Yasseri A, Mohammadi A, Aghamir SM. Management of a lost stone during laparoscopic ureterolithotomy: video article. Transl Res Urol. 2021;3(1):38-9.

4. Aghamir SM, Dadkhah Tehrani F, Khatami F, Zia H. Second-look percutaneous nephrolithotomy: access to the tract with direct vision and fluoroscopic guidance. Transl Res Urol. 2020;2(4):118-22.
5. Abolyosr A (2007) Laparoscopic transperitoneal ureterolithotomy for recurrent lower-ureteral stones previously treated with open ureterolithotomy: initial experience in 11 cases. J Endourol 21(5):525-529. https:// doi.org/10.1089/end.2006.0354

6. Gaur DD, Trivedi S, Prabhudesai MR, Madhusudhana HR, Gopichand M (2002) Laparoscopic ureterolithotomy: technical considerations and longterm follow-up. BJU Int 89(4):339-343. https://doi.org/10.1046/j.14644096.2001.01562.x

7. Chahin F, Dwivedi AJ, Paramesh A, Chau W, Agrawal S, Chahin C et al (2002) The implications of lighted ureteral stenting in laparoscopic colectomy. JSLS 6(1):49-52

8. Fakhr Yasseri A, Hamidi M, Aghamir SM. Comparison of stone-free rates after ureteroscopic pneumatic lithotripsy in impacted vs. non-impacted upper ureteral stones. Transl Res Urol. 2019;1(2):79-83.

9. Mandhani A, Kapoor R (2009) Laparoscopic ureterolithotomy for lower ureteric stones: steps to make it a simple procedure. Indian J Urol 25(1):140-142

10. Shokohideh V, Mashhadi R. Ultrasound-guided paravertebral block compare to the intravenous tramadol for pain control in percutaneous nephrolithotomy. Transl Res Urol. 2019;1(1):43-5.

11. Vorreuther R (1992) Minimally invasive ureteroscopy using adjustable electrohydraulic lithotripsy. J Endourol 6(1):47-50

12. Honeck P, Wendt-Nordahl G, Krombach P, Bach T, Häcker A, Alken P et al (2009) Does open stone surgery still play a role in the treatment of urolithiasis? Data of a primary urolithiasis center. J Endourol 23(7):1209-1212. https://doi.org/10.1089/end.2009.0027

13. Watson GM, Landers B, Nauth-Misir R, Wickham JEA (1993) Developments in the ureteroscopes, techniques and accessories associated with laser lithotripsy. World J Urol 11(1):19-25

14. MacDermott JP, Grove J, Clark PB (1993) Laser lithotripsy with the candela MDL-2000 laser tripter. Br J Urol 71(5):512-515. https://doi.org/10.1111/j. 1464-410X.1993.tb16016.x

15. Harewood LM, Webb DR, Pope AJ (1994) Laparoscopic ureterolithotomy: the results of an initial series, and an evaluation of its role in the management of ureteric calculi. Br J Urol 74(2):170-176

16. Bellman GC, Smith AD (1994) Special considerations in the technique of laparoscopic ureterolithotomy. J Urol 151(1):146-149

17. Keeley FX, Gialas I, Pillai M, Chrisofos M, Tolley DA (2001) Laparoscopic ureterolithotomy: the Edinburgh experience. BJU Int 84(7):765-769. https://doi.org/10.1046/j.1464-410x.1999.00287.x

18. Shabaninia S, Yahyazadeh SR, Mousavi A, Kasaeian A. The characteristics and outcomes of patients treated with percutaneous nephrolithotomy according to the preoperative renal function levels. Transl Res Urol. 2020;2(1):4-8.

\section{Publisher's Note}

Springer Nature remains neutral with regard to jurisdictional claims in published maps and institutional affiliations.

\section{Submit your manuscript to a SpringerOpen ${ }^{\circ}$ journal and benefit from:}

- Convenient online submission

- Rigorous peer review

- Open access: articles freely available online

- High visibility within the field

- Retaining the copyright to your article

Submit your next manuscript at springeropen.com 